\title{
Erratum to: Geochemical Features of the Moon and Earth Predetermined by the Mechanism of Formation of the Earth-Moon System (Report at the 81st International Meteorite Conference, Moscow, July 2018) [Geochemistry International, 2019, Vol. 57, No. 8]
}

\section{E. M. Galimov*}

Vernadsky Institute of Geochemistry and Analytical Chemistry (GEOKhI), Russian Academy of Sciences, Moscow, 119991 Russia

*e-mail: galimov@geokhi.ru

Submitted August 14, 2019; accepted for publication August 14, 2019

DOI: $10.1134 /$ S0016702919100100

Fig. 5 should read as follows:

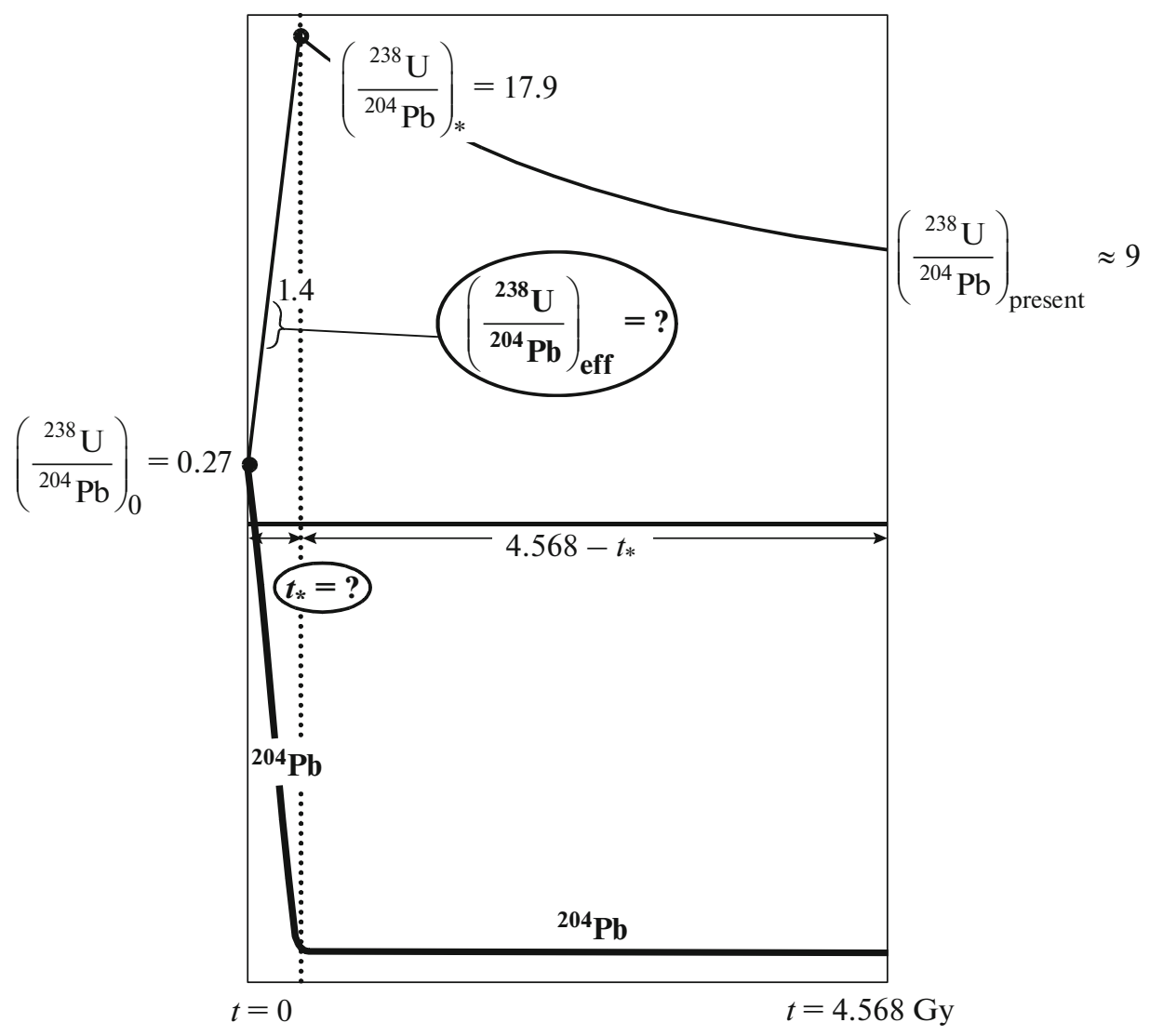

Fig. 5. Changes in the proportions of isotopes in the ${ }^{238} \mathrm{U} /{ }^{204} \mathrm{~Pb}$ system because of the loss of the ${ }^{204} \mathrm{~Pb}$ isotope during the disperse stage (during accretion starting at $t=0$ till $t=t_{*}$ ) and ${ }^{238} \mathrm{U}$ decay at an unchanging ${ }^{204} \mathrm{~Pb}$ concentration when the planet existed (from $t_{*}$ till $4.568 \mathrm{Ga}$ ). Relationships of similar meaning occur in the ${ }^{235} \mathrm{U} /{ }^{204} \mathrm{~Pb}$ system (Galimov, 2011).

The original article can be found online at https://doi.org/10.1134/S0016702919080044 